\title{
Seguimiento al comportamiento del mercado de tierras rurales a través de un GIS, Santander Colombia
}

\section{Tracking the behavior of rural land market through a GIS, Santander Colombia}

\author{
RiCARDO LOZANO-BotaCHE*
}

\begin{abstract}
In spite of the legal frames and public policy, property rights over land are still usurped using violent methods in some countries. This research, from its reference frame of land management, neo-institutionalism and computational tools, generically known as Geographical Information Systems, presents an observatory of regional prices, and with the data sequence and its informatics processes can be maintained over time as a reference in agrarian processes, land restitution for victims of dispossession and in the implementation of projects of social or economic development.
\end{abstract}

Keywords: price of agricultural land, land markets, land management, property rights.

\section{Resumen}

A pesar de los marcos legales y políticas públicas, en algunos países, los derechos de propiedad sobre la tierra siguen siendo usurpados o impedidos con métodos violentos. Este trabajo de investigación, desde el marco de referencia de la Administración de Tierras, el Neoinstitucionalismo y las herramientas computacionales -conocidas genéricamente como Sistemas de Información Geográfica (GIS, por sus siglas en inglés) - presenta un modelo de observación regional de precios que, por la secuencia de datos y su proceso informático, puede mantenerse a través del tiempo como referente en procesos agrarios de restitución de tierras a víctimas del despojo, así como en la ejecución de proyectos de desarrollo social o económico.

Palabras clave: precio de la tierra de uso agrícola, mercados de tierras, administración de tierras, derechos de propiedad.

* Universidad Santo Tomás de Colombia, Colombia. Correo-e: ricardolozanobotache@gmail.com 


\section{Introducción}

En el mundo es reconocido el conflicto armado interno colombiano y sus efectos en la sociedad, la economía, el ambiente y las relaciones internacionales; el conflicto y sus causas han sido profunda y profusamente analizados, considerando a la cuestión agraria ${ }^{1}$ como uno de los factores determinantes.

El crecimiento de los centros urbanos colombianos no obedeció fundamentalmente a la dinámica del sector industrial que demandaba fuerza laboral, sino que se mantuvo el modo feudal y semifeudal de relaciones económicas y sociales, posterior a la independencia de la corona española. Es así que la tierra sigue siendo una propiedad que implica poder para algunos grupos sociales; es el recurso que los campesinos consideran esencial para su producción, y para algunos inversionistas interesados en lograr utilidades derivadas de su fertilidad u otros recursos subyacentes, es un bien disponible.

En 2011 se aprobó en Colombia la ley 448 sobre medidas de atención, asistencia y reparación integral a las víctimas del conflicto armado interno que incluyó, en su aspecto medular, la restitución de tierras a las personas propietarias, poseedoras u ocupantes de un terreno que sufrieron despojo a través de la fuerza o la intimidación. En 2013 se comenzaron a ejecutar sentencias judiciales de restitución de tierras, sustentadas, en parte, en procesos de identificación de la propiedad que en algunos casos ya no eran fácilmente reconocibles, por lo que se acudió a la descripción de títulos de dominio, escrituras notariales, planos de catastro y levantamientos topográficos para la determinación de los linderos antes de los hechos de usurpación.

El artículo 72 de la ley 448 de 2011 expone que: "El Estado colombiano adoptará las medidas requeridas para la restitución jurídica y material de las tierras a los despojados y desplazados. De no ser posible la restitución, para determinar y reconocer la compensación correspondiente" (Diario Oficial, 2011).

Queda expuesta, entonces, la necesidad de conocer el precio de la tierra y las conexiones legales que son inherentes a esa determinación, entendiendo que la tasación es sobre valores al momento de haberse dado

${ }^{1}$ La cuestión agraria es reconocida desde la literatura social y económica como un estado no deseado de conflicto entre los intereses de campesinos, apegados a subsistir con formas tradicionales de producción y el modelo capitalista de producción agropecuaria. De ser un concepto derivado originalmente del análisis marxista, en la actualidad, en general, se refiere al problema de la población rural dedicada a la agricultura y la ganadería frente a la usurpación de la tierra, el cultivo de narcóticos, la violencia impuesta por grupos delincuenciales y el abandono del Estado. 
el hecho punible; se desarrolla un procedimiento para establecer el estado preexistente de la explotación económica, objeto de la demanda.

$\mathrm{Al}$ momento de escribirse este artículo no se conocían casos conducentes a la "compensación en dinero" que "sólo procederá en el evento en que no sea posible ninguna de las formas de restitución”, como lo deja claro el párrafo cinco del mismo artículo, no obstante va perfilándose la importancia de contar con un mecanismo que, a través del tiempo y de manera técnica, informe la evolución del precio de la tierra de uso agrícola (Diario Oficial, 2011).

El capítulo III de Plan Nacional de Desarrollo 2010-2014 (DNP, 2014: 52), que hace referencia al crecimiento sostenible y la competitividad, reconoce en el sector agropecuario la potencialidad de ser uno de sus impulsores, pero también la necesidad de ajustar algunos factores de importancia estratégica, entre ellos el de la institucionalidad de la tierra, pues en el mismo documento se plantean problemas por resolver alrededor de sus derechos de propiedad.

A la circunstancia política y social se adiciona el estado de calamidad por inundaciones en que quedó gran parte de la población dedicada a la producción agropecuaria durante el último trimestre de 2010, que hizo necesaria la declaratoria, por parte del gobierno, del estado de emergencia económica, social y ecológica, por razón de grave calamidad pública, mediante el Decreto 4580 del 7 de diciembre de 2010 (Ministerio del Interior y la Justicia, 2010). En 2013, las manifestaciones públicas, la toma de carreteras y el desabastecimiento fueron el reflejo de la ineficacia de las medidas tomadas tres años antes y la pésima interpretación de la cuestión agraria en su sentido más amplio.

El panorama esbozado desde lo político y lo socioeconómico permite apreciar varios aspectos por resolver en las cuestiones específicamente de la tierra: El primero es la necesidad de consolidar la institucionalidad de los derechos de propiedad porque son determinantes de estabilidad social; un segundo aspecto tiene que ver con la necesidad de recuperar y asegurar un sistema de identificación predial que permita la correspondencia entre lo que legalmente es un derecho de propiedad y su realidad física; tan urgente es esto como actuar aportando mejoras en los sistemas de información pública de precios, de forma que sea posible disminuir la distorsión en los mercados de tierras y operar datos para la conservación histórica del precio.

Los servicios de administración de tierras en Colombia se han limitado desde el marco legal al mantenimiento del sistema de registro y el sistema de catastro, pero aún no logran alcanzar un nivel de eficiencia que coadyuve a mantener la institucionalidad necesaria para salvaguardar los derechos de propiedad, el esfuerzo institucional y las políticas públicas 
concurrentes al desarrollo del medio rural en todas sus posibilidades es desbordado por la presión que todavía en el siglo XXI se percibe por la posesión de la tierra como factor de poder, ${ }^{2}$ más allá de su capacidad agrológica productiva. Exponen Rey et al. (2014: 31) que la tenencia de la tierra es la relación, definida en forma jurídica o consuetudinaria, en cuanto individuos o grupos, con respecto a la tierra; es un conjunto de normas creadas por las sociedades para regular su comportamiento, al establecer cómo asignarse socialmente los derechos de propiedad de la tierra y el acceso a los derechos de usar, controlar y transferir la tierra, así como sus correspondientes responsabilidades y limitaciones. Entonces, de acuerdo con estos autores, la tenencia de la tierra desempeńa un papel importante en la estructura social, política y económica; siendo evidente para el mundo que en Colombia el acceso a la tierra ha sido fuente de poder político y de conflicto social desde las últimas cinco décadas.

El documento Compes 3641 (DNP, 2010: 23) definió la Política Nacional para consolidar la Interrelación del Catastro con el Registro, en el marco de la estrategia para reducir la pobreza y la desigualdad, la cual identifica los ejes problemáticos relacionados principalmente con las deficiencias en el intercambio, unificación, mantenimiento y acceso a la información, tanto catastral como registral, por parte de todos los actores que participan en dicho proceso. A los instrumentos puestos en acción, derivados de esa acción de política pública, y a los que les son inherentes beneficios sociales, se les han imputado prácticas delictivas que actualmente desvirtúan la esencia de las iniciativas y han producido el efecto

${ }^{2}$ Las fuerzas en conflicto han desplazado de sus propiedades a los habitantes rurales dentro de su estrategia de consolidación territorial; mientras el Juzgado Segundo Civil del Circuito Especializado en Restitución de Tierras de Ibagué, el 28 de agosto de 2013 dictó sentencia restitutoria a favor de Clementina Cuellar, Ramiro Molina y Abraham Andrade por despojo de que fueron víctimas por las Fuerzas Armadas Revolucionarias de Colombia (FARC), Radicado No. 73001-31-21-002-2013-00038-00. El 20 de febrero de 2013, el presidente de Colombia afirmó en entrevista para el diario El Tiempo, que recuperaría de las FARC 130,000 hectáreas en San Vicente del Caguán, 308,000 hectáreas en La Macarena y en el parque nacional Tinigua 22,000 hectáreas; también, existen informes oficiales de la Unidad de Restitución de tierras del 7 de octubre de 2013 en relación con el reclamo de tierras en la hacienda las Tangas -ubicada en el corregimiento de Villanueva, en el municipio de Valencia, Departamento de Córdobalas cuales están en manos del sindicado por la masacre de Pueblo Bello, Gildardo Ospina Muñetón, alias "San Tropel”. La hacienda las Tangas fue el principal centro de operaciones de los grupos paramilitares en Colombia, liderados por los hermanos Castaño Gil; expuso la Unidad de Restitución de Tierras que allí no sólo se gestaron los más macabros planes con los que se fortaleció y expandió el grupo, sino que se dieron masacres, torturas y todo tipo de actos terroristas en contra de la sociedad civil. 
contrario, pues se han levantado denuncias públicas ${ }^{3}$ y penales sobre falsificación de títulos, registros irregulares y despojo de la propiedad.

Paralelamente, en Colombia se han incrementado los contratos de concesión minera en los últimos años, ${ }^{4}$ propiciándose cambios en el uso del suelo y nuevas dinámicas económicas que inciden en los derechos de propiedad sobre la tierra y los ecosistemas, ya que el derecho minero tiene instituidos sistemas de registro y catastro minero análogos a los que regulan la propiedad agraria, lo que da lugar a la transposición espacial de derechos y superposición de normatividades: las leyes agrarias enmarcadas dentro del derecho civil, el código de minas y la normatividad ambiental. Sin entrar en las consideraciones ambientales ni en las incidencias económicas de la minería, este párrafo tiene como propósito seńalar un elemento en la complejidad de los temas relacionados con la tierra y las implicaciones inherentes a su acceso como bien o activo, así como a las formas de mantener el derecho de propiedad sobre ella.

En el departamento de Santander, las tierras de uso agropecuario han sido incididas por proyectos de ingeniería para el desarrollo de infraestructura como la construcción de la hidroeléctrica del Sogamoso, sistemas mineros como los del Distrito Vetas-California, fenómenos climáticos como el de la niña, en 2010, y demandas especulativas ${ }^{5}$ en zonas aledañas a los corredores viales (en zonas tradicionalmente ganaderas como Bajo Rionegro o en zonas palmeras como las del magdalena medio).

Actualmente no existe un sistema de información que sea solvente en la operación de las variables que intervienen en la formación de precio de la tierra de uso agrícola ni la forma en que éste se comporta, asimismo, se carece de elementos que coadyuven en la información de atributos del bien ofertado y se sigue necesitando, sobre todo, transparen-

\footnotetext{
${ }^{3}$ El jueves 3 de marzo de 2011 la revista Semana presentó en su edición digital declaraciones del Superintendente de Notariado y Registro, Jorge Enrique Vélez, haciendo referencia a tierras usurpadas con complicidad de funcionarios públicos: "15,000 hectáreas se encontraron en Mapiripán; 30,000, en Chocó; 34,000, en los Montes de María; 20,000, en el oriente antioqueño y 30,000 más provenientes de una nueva modalidad de ciudadanos que tienen una finca y al lado un predio baldío y hacen la titulación de los linderos y se van quedando con esos predios". En la misma nota periodística se menciona la siguiente expresión de Juan Manuel Santos, presidente de Colombia, refiriéndose al Superintendente: "Me dijo: 'donde ponemos el dedo, en cualquiera de las oficinas de registro, sale pus, corrupción total'”.

${ }^{4}$ En Ministerio de Minas informa que fueron 1,733,643 las hectáreas de concesión asignadas entre 2008 y 2010 (Ministerio de Minas y Energía, 2011).

${ }^{5}$ En 2010 una hectárea de tierra de uso agrícola costaba en algunas zonas del municipio de Vélez \$50,000,000 de pesos, esto representa 97 salarios mínimos mensuales del mismo ańo, si una Unidad Agrícola Familiar (UAF) en ese municipio es de 18 hectáreas, según el Instituto Colombiano de Desarrollo Rural (Incoder), una familia debe destinar un salario mínimo durante 145 ańos exclusivamente para adquirir su tierra. Cifras entregadas por Darío Echeverry, secretario de Agricultura del Departamento de Santander en entrevista con el diario económico La República y el 31 de marzo de 2010, coincidente con la información de mercado obtenida por los autores de este proyecto, uno de ellos es perito valuador con licencia nacional.
} 
cia en los mercados; prevalece la necesidad de precisión en la información que opera dentro del mercado de la tierra de uso agrícola, por ser ésta el activo determinante en el desarrollo de proyectos empresariales privados, pero, sobre todo, por ser el recurso más importante para los habitantes rurales dedicados a la agricultura, en el entendido de que es el fundamento de su existencia como campesinos y el factor que facilita el acceso al crédito.

Un sistema de información preciso sobre los atributos físicos y geográficos de los predios rurales también ayuda a salvaguardar los derechos de propiedad en el caso de una transacción, también aporta en la solución a un proceso legal por posesión irregular o cuando es forzoso el abandono temporal de la tierra por causas naturales o de conflicto social. En esencia, es importante contar con un sistema de información que coadyuve efectivamente a la transparencia de los mercados y a la consolidación de los derechos reales de la propiedad de la tierra.

En las culturas occidentales sería difícil imaginar una sociedad sin derechos de propiedad como un impulsor básico para el desarrollo y el crecimiento económico. La propiedad no es sólo un activo económico, la información transparente sobre los derechos reales de propiedad proporcionan un sentido de identidad y pertenencia que va mucho más allá de la simple tenencia y sustenta los valores de la democracia y la libertad humana. Por lo tanto, los derechos de propiedad se gestionan normalmente bien en las economías modernas donde la información catastral apoya la creación de espacios de convivencia (FIG, 2014).

\section{El cambio institucional}

Las cuestiones sobre la tierra en Colombia ofrecen muchos temas para su estudio; para esta investigación fue necesario definir un referente teórico que permitiera el abordaje del tema específico de la administración de las tierras y las reglas de juego que se han dado para su uso como factor productivo y como derecho de propiedad desde el contexto legal y social. El neoinstitucionalismo, especialmente en la versión del Nobel de Economía, Douglas North, permitió la visión multidisciplinaria de los procesos sociales y la identificación de la trayectoria histórica con el propósito de evaluar las posibilidades de cambio institucional.

Resultó pertinente establecer como partida, siguiendo a North, que las instituciones son las reglas del juego en una sociedad, o más formalmente son las limitaciones ideadas por el hombre que dan forma a la interacción humana y, por lo tanto, estructuran incentivos en el intercambio humano, sea político, social o económico. "El cambio institucional conforma el modo en que las sociedades evolucionan a lo largo del 
tiempo, por lo cual es la clave pura para entender el cambio histórico" (North, 1995: 13).

En el caso que nos ocupa se observó que se ha evolucionado institucionalmente desde la Colonia y la república hasta las nuevas propuestas para optimizar sistemas de información que mejoren la administración de tierras y den transparencia a los mercados, se ha pasado por modos de híbridos de producción feudal, esclavista y capitalista con varios matices entre proteccionistas y liberales.

Especial atención causó el análisis de la ley de $1821^{6}$ (Place, 1825) - expedida en el marco reglamentario de la Convención de Villa del Rosario sobre enajenación de tierras baldías y creación de oficinas de agrimensura-, la cual consideró que uno de los primeros deberes de la república era fomentar la agricultura por cuantos medios estén a su alcance; que la enajenación de tierras baldías a precios cómodos y equitativos debería contribuir poderosamente a ese objeto y que los productos de esta enajenación eran necesarios para cubrir los gastos y erogaciones a que estaban sujetas las rentas públicas.

Se decretó, entonces, la enajenación en las provincias marítimas y en las del interior, las tierras baldías que no habían sido antes concedidas a persona alguna o que habiéndolo sido por composición volvieron al dominio de la república según lo dispuesto por las leyes anteriores.

Lo crucial para este trabajo de investigación es que con la mencionada ley de 1821 se estructuró, además de una forma de tasación y pago de las tierras, el sistema de agrimensura en la república naciente y los cargos de agrimensor general y de agrimensores delegados para registrar las propiedades rurales de todos los ciudadanos y extranjeros residentes.

Se dieron cuatro años, contados desde la publicación de la ley, para que todos los ciudadanos y extranjeros residentes en Colombia registraran sus propiedades rurales en las oficinas particulares de cada provincia; se dispuso que desde ese tiempo ningún juez ni escribano podría autorizar contratos de compra y venta de dichas propiedades sin que se acompañara de un certificado y un plano del agrimensor, previa verificación.

Se consideró que si pasados cuatro años, los propietarios no cumplían con el registro prevenido, sus tierras serían adquiridas por merced o composición y se reincorporararían al dominio de la república; en caso de haber sido adquiridas por compras sucesivas a otros títulos, el gobierno haría practicar los registros a expensas de los propietarios.

\footnotetext{
${ }^{6}$ Se analizó el documento digitalizado por la Biblioteca Virtual del Banco de la República en 2005 "Documentos que hicieron un país" del Archivo General de la Nación que es, a su vez, un texto resumido del libro Cuerpo de Leyes de la Republica de Colombia, consultado en Indiana University Library.
} 
Considero que al no aplicar esta ley de manera efectiva se perdió históricamente la oportunidad de ordenar, desde el nacimiento de la república, la propiedad rural y los derechos que le son inherentes.

En el proceso de evolución y transformación han existido hechos sociales que inciden en la institucionalidad de la tierra, así como nuevas cosmogonías que han transformado las reglas del juego; de hecho, el progreso científico-técnico actualmente contrarresta en gran medida las restricciones de fertilidad o extensión de los suelos, de tal manera que la tierra en sí misma no es factor productivo determinante. Hoy es fundamental el complemento intelectual y tecnológico, luego las reivindicaciones por la tierra "es de quien la trabaja" como propósito sublime de muchas organizaciones sociales durante gran parte del siglo pasado se queda corto como expectativa liberadora de la pobreza del habitante rural del siglo XXI.

Otro cambio institucional es que el poder político, económico y social en Colombia ya no es exactamente coincidente con la propiedad de la tierra aunque en algunas zonas aún lo siga siendo; con la urbanización del país, el Producto Interno Bruto (PIB) agropecuario representa mucho menos que hace cincuenta ańos y muchas actividades rurales ya no son agropecuarias. La tierra como factor productivo ahora pesa menos al evaluar el origen de la renta nacional.

Son las coberturas del suelo, es decir, la capacidad productiva de las praderas y los cultivos, junto con la infraestructura transformadora y la tecnología blanda de mercadeo, las determinantes del logro económico del sector agropecuario. Acerca de este cambio en las reglas del juego, autores como Balcázar-Vanegas et al. (2001: 38), apuntan que es el progreso técnico y el cambio institucional, la principal fuente del crecimiento de la producción, y que la forma como se distribuye el ingreso nacional obedece cada vez menos a la distribución inicial de la propiedad y cada vez más a la habilidad y capacidad de gestionar en forma superior los recursos productivos.

Independientemente de la relación de propiedad inicial, la clave de la prosperidad y libertad de los seres humanos estará cada vez más en relación con la calidad y cantidad de sus conocimientos, el sector rural y las actividades agropecuarias no son la excepción. Si bien la tierra es para la mayoría de las personas una aspiración natural, y tal vez remanente evolutivo - por cierto sublime- al punto de que quien progresa económicamente desea adquirir una propiedad rural, no parece ser ahora condición necesaria para desarrollar emprendimientos agrícolas, al contrario, invertir capital en tierras puede distraer recursos necesarios para agregar valor; de esta forma no son los derechos de propiedad un requerimiento indispensable, lo son más los derechos de uso, por ejemplo, el caso del arriendo. 
En Colombia, desde el 2003, el Instituto Colombiano de Desarrollo Rural ha sustituido el instrumento de dotación de tierras por el de asignación, dejando que la figura de compra de derechos quede postergada para años después, cuando los proyectos de desarrollo sean sostenibles y generen excedentes para el pago de la cuota-parte del precio de la tierra no subsidiada.

La institucionalidad de la tierra ha presentado transformaciones que se consideran profundas pero todavía no revolucionarias; esos cambios incrementales de los aspectos formales expresados normativamente, las políticas públicas y las expresiones sociales por el acceso a su propiedad pueden ser comprendidos desde este marco teórico, si complementamos con que la función principal de las instituciones en la sociedad es reducir la incertidumbre al establecer una estructura estable, aunque no necesariamente eficiente, de la interacción humana.

Las anteriores líneas se han ordenado con la intención de consolidar el marco para asumir el estudio propuesto, se articula en ellas la cuestión de tierras, las ideas, las creencias, las ideologías, las normas, las acciones y los cambios dados dentro del periodo de análisis; el cambio institucional y tecnológico se perfilan desde lo expuesto como las claves de la evolución social.

Las instituciones y las tecnologías inciden dentro de la administración de tierras, sus cambios incrementales y su incidencia dentro de la búsqueda del desarrollo rural, pues, tal como afirma North (1995: 135-136): "El cambio económico a largo plazo es la consecuencia acumulativa de muchas decisiones de corto alcance de empresarios políticos y económicos que directa e indirectamente (por medio de efectos externos) dan forma al desempeño".

La política pública de los últimos veinte años ha pretendido modificar las distorsiones del sector rural dedicado a la agricultura, reconociendo el fracaso del intervencionismo oscilante entre paternalismo y burocratismo. Se intenta ahora promover mercados que acudan al arriendo, la hipoteca, la asociatividad, entre otras, de forma que el mercado ayude a ir consiguiendo precios económicamente razonables.

Judy Wallace (2009: 2-15) ayuda a la comprensión de las actuales cuestiones de la tierra cuando afirma que, actualmente, la caja de herramientas tiene elementos de la topografía geomántica y del derecho, que universalmente facilitan el acceso a las potencialidades del recurso suelo para un nuevo constructo que se anticipe a la controversia de la propiedad en sí misma, por lo que buenos sistemas de información y demarcación acompańados de políticas públicas que favorecen el acceso a las potencialidades de la tierra, derechos de propiedad y derechos de uso, pueden hacer confluir los intereses públicos y privados en el camino hacia el desarrollo. 
Acudir a las tecnologías de punta en la identificación de la propiedad y la determinación de su valor podrá coadyuvar en la superación de métodos tradicionales, que sólo dan cuenta de referencias geográficas o arcifinias que exponen a la inseguridad en los derechos de propiedad; todavía la propiedad en Colombia tiene identidad y valor sustentada en textos que certifican un bien inmueble tan sólo como un cuerpo cierto, así se define el objeto de la transacción. El cuerpo cierto es el bien inmueble como lo percibió con sus sentidos el comprador ante la ilustración que le ofrece el vendedor, dejándose constancia de que la cabida y los linderos citados son sólo una aproximación al bien transado.

Como lo expresa Pérez-Salazar (2006: 307), sin duda, esta figura tiene valor práctico para referir bienes inmuebles, objeto de transacciones en ámbitos socialmente consolidados, donde la tierra no se disputa por medio de conquista. Pero, como también lo señala, su trasplante a contextos sociales y políticamente inestables e inequitativos -como los que predominan desde la llegada española- probablemente no contribuye a aclimatar un ordenamiento jurídico; "por lo anterior, hay mucha coincidencia entre autores de tema de tierras, que la ambigüedad en que se incurre al describir un predio mediante la figura del "Cuerpo Cierto" dio origen a la parte de la violencia que con la disculpa de la tierra se sucede en Colombia”.

Con respecto a la dificultad de identificar físicamente la propiedad rural, sucede que en algunas ocasiones no hay certeza del derecho reconocido en las sentencias proferidas y sustentadas en la Ley de tierras mencionada en párrafos anteriores; aunque el derecho de propiedad judicialmente se reconoce, ha sido urgente ordenar a entidades como el Instituto Colombiano de Desarrollo Rural (Incoder) o el Instituto Geográfico Agustín Codazzi (IGAC) que adelanten las gestiones pertinentes para determinar las características físicas del predio restituido o formalizado, carga que debe ser agotada en el proceso administrativo. La exigencia administrativa está requiriendo una rápida actualización institucional que todavía en 2014 no evidencia respuestas efectivas (ORRDP, 2014).

Deininger et al. (2012: 27-35) han expuesto que para los países que construyen su entrada al desarrollo social y humano, la administración de tierras es decisiva y técnicamente compleja porque trasciende muchas disciplinas, tal es el caso del derecho, las tecnologías de la información, la geodesia, la topografía, la economía, la planificación urbana, la antropología y las ciencias ambientales, sociales y políticas. Algunos de estos ámbitos, como los sistemas de información georreferenciadas GIS, están avanzando rápidamente, por lo que es importante no quedarse con soluciones obsoletas y, en cambio, diseñar sistemas con capacidad estratégica de anticipación a futuras necesidades. 
Expresa la Organización de las Naciones Unidas-Habitat (UN-Habitat, 2008) que los sistemas de administración de la tierra efectivos y bien adaptados facilitan la realización de las metas de las políticas públicas, puesto que los servicios relacionados con la tierra alcanzan a todos los usuarios del suelo, incluyendo a los más pobres y vulnerables, así como también a los inversores comerciales.

En este entendido, si se quiere lograr que los derechos al suelo sean efectivamente seguros, que se mejore el acceso, que las asignaciones de tierra sean más justas, que sea más productivo y la demanda mejor atendida con la oferta disponible, hay dos condiciones obligadas: lograr acuerdos institucionales para la administración de la tierra asequibles a todos (los cuales se obtienen más fácilmente de una manera descentralizada porque pueden responder a prioridades locales en vez de con sistemas altamente centralizados) y sistemas de información del suelo amplios y actualizados (que puedan captar la complejidad de la ocupación actual del suelo, su uso y reivindicaciones, incluyendo el conjunto de derechos que se sobreponen). Lo anterior sobreentiende los valores de la tierra y los mecanismos de su mercado.

Los sistemas de información que faciliten los mercados proporcionan el acceso equitativo a la tierra y el aseguramiento de este activo como patrimonio. Las mayores ganancias en América Latina y Asia por las actividades agropecuarias están probablemente explicadas por el hecho de que en estas regiones la titulación es la vía dominante para asegurar los derechos de la tierra; no sucede lo mismo en África donde la tenencia de títulos de propiedad es más precaria, pues la propiedad se sustenta principalmente en arreglos consuetudinarios (Lawry et al., 2014).

Se reitera que en la cuestión de tierras, el sistema de mercado no puede ser visto exclusivamente como un mecanismo para transferir bienes en un lugar de libre concurrencia pues, además de los aspectos de transacción y acuerdo de precio, debe tenerse siempre presente que en un sentido más amplio el mercado es el principio fundamental de la organización de la vida económica, pero también que sin la intervención inicial del Estado, proveedor de la tierra nación y regulador de las reglas de la propiedad formal, no puede surgir un sistema impulsor del desarrollo rural basado en el mecanismo de mercado de tierras. Se entiende que un mercado que funciona presupone no sólo la prevención de la violencia y el fraude, sino, además, la protección de ciertos derechos tales como la propiedad y la imposición de contratos.

Las instituciones, en comparación con organizaciones públicas o privadas, deben ser vistas como códigos sociales creados por la sociedad para estructurar la interacción política, económica y social, éstas pueden ser de carácter informal: costumbres, tradiciones, códigos de conducta o 
formales como constituciones o leyes que determinan los costos de producción, así como también de transacción, y de este modo la utilidad y viabilidad de participar en cualquier actividad económica.

Al considerar que el mecanismo de mercado se basa en el intercambio de derechos de propiedad obtenidos legalmente, este sistema sólo puede operar con éxito si existen suficientes propiedades formales para ser intercambiadas en una economía a gran escala, así como instituciones que hagan respetar los derechos.

Entre los cambios más importantes que deben hacerse en las instituciones se encuentra el acceso de las mujeres a los derechos sobre la tierra y, en consecuencia, a la ampliación de sus posibilidades y oportunidades: derecho a adquirirlas a través de la titulación, acceso al crédito, a los mercados, a la educación, servicios de extensión, tecnología e incluso la vocería pública; las anteriores son condiciones esenciales para hacer efectivo el uso de cualquier derecho a la tierra que pudieran haber logrado (Spichiger et al., 2013).

El sentimiento de apego a la tierra y el significado social que inspiró el intervencionismo del Estado en el siglo pasado sigue siendo respetable, pero ahora tiene igual importancia pensar en ella como un activo que debe ser capaz de retornar excedentes monetarios suficientes para ser considerados renta, de aquí la necesidad de observar el comportamiento de los precios en busca de la transparencia en los mercados y la correcta asignación de recursos públicos o privados.

\section{Metodología}

Construir un modelo que permita conocer la tendencia del precio de la tierra requiere conocer con veracidad los valores de transacción, esto es un ideal debido a que no es lo formalmente informado, pues cuando se acude a las estadísticas de notariado y registro se observa que las cifras reportadas por los vendedores y compradores no son razonablemente parecidas a las ofertas de venta publicitadas en los avisos del mercado inmobiliario o las ofertas informalmente puestas a la vista del público sobre los mismos bienes.

Lo anterior se ha precisado también en estudios del mercado de tierras, mediante análisis cuantitativos y cualitativos que han conducido a develar prácticas comunes de evasión y elusión de impuestos a las operaciones de compra venta en Colombia.

En la metodología se procedió a levantar información de ofertas del mercado, se efectuaron encuestas directamente en el sitio o terreno ofertado, mediante el método no probabilístico de muestreo discrecional por municipios de las provincias de Santander, se preguntaron datos a quienes 
atendieron la solicitud como propietarios o encargados de informar o mostrar la propiedad en venta. Se utilizó el método no probabilístico porque lo que se busca es evaluar el alcance que tiene usar la herramienta tecnológica SIG en el contexto del mercado y la administración de tierras, así como sus implicaciones sociales en relación con el aseguramiento de los derechos de propiedad y no la precisión o evaluación cuantitativa de los datos del mercado, pues esto sería tema de interés de otro estudio sobre precios de mercado y su comportamiento. Antes de cualquier respuesta se presentó al entrevistado el propósito académico de la información y los siguientes aspectos legales:

1. La discrecionalidad en el manejo de la información que tiene una operación de compraventa inmobiliaria.

2. Lo preceptuado en la Ley estatutaria 1266 de 2008 (República de Colombia, 2008) por la cual se dictan las disposiciones generales del habeas data y se regula el manejo de la información contenida en bases de datos personales, en especial la financiera, crediticia, comercial, de servicios y la proveniente de otros países.

3. La costumbre mercantil, regulada en el artículo $3^{\circ}$ del Código de Comercio Colombiano que expresa: "La costumbre mercantil tendrá la misma autoridad que la ley comercial, siempre que no la contraríe, manifiesta o tácitamente, y que los hechos constitutivos de la misma sean públicos, uniformes y reiterados en el lugar donde hayan de cumplirse las prestaciones o surgido las relaciones que deban regularse por ella. En defecto de costumbre local se tendrá en cuenta la general del país, siempre que reúna los requisitos exigidos en el inciso anterior" (Diario Oficial, 1971).

4. Sentencia de la Corte constitucional T-729- 02 que expresa en una de sus partes: "para la Corte, la recopilación y publicación de la información contenida en la base de datos de catastro está sometida a los principios de la administración de datos, precisamente porque la misma está conformada por datos personales mediante los cuales se asocia una realidad patrimonial con una persona determinada [...] la sala considera lo siguiente: con la publicación de la base de datos sobre la información catastral de Bogotá en la Internet, tal y como está dispuesta, el Departamento administrativo de Catastro, vulnera el derecho fundamental a la autodeterminación informática del demandante. En consecuencia, se torna indispensable conceder la tutela invocada y ordenar a la respectiva entidad que haga cesar la conducta vulneradora del derecho, de tal forma que en adelante se abstenga de publicar, con posibilidad de acceso indiscriminado y sin el consentimiento previo y libre, in- 
formación personal del actor" (Corte Constitucional de Colombia, 2002: 1-23).

La toma de información se realizó mediante un dispositivo móvil tipo Handheld modelo Nautiz X3 que maneja bases de datos y georreferencia de puntos en terreno con señal GPS sobre una base cartográfica y procesos estadísticos de datos.

Con la actuación de personal contratado para la toma de información y la gestión de la base de datos se procedió a la búsqueda de las ofertas del mercado y el contacto con los agentes que intervienen en el mercado de las tierras como inmobiliarias, avisos de prensa y sobre todo a la búsqueda de propietarios que instalan avisos de venta directa. Se presentan a continuación ejemplos de avisos instalados por propietarios que fueron encontrados durante los recorridos de campo, se efectuaron las llamadas de primer contacto y a quienes lo permitieron se le hicieron las visitas de campo, también se acudió a las entrevistas en días de mercado y los avisos en tiendas e inmobiliarias, como se observa en el siguiente registro fotográfico.

\section{Registro fotográfico de avisos de predios en venta en diferentes zonas del Departamento de Santander}
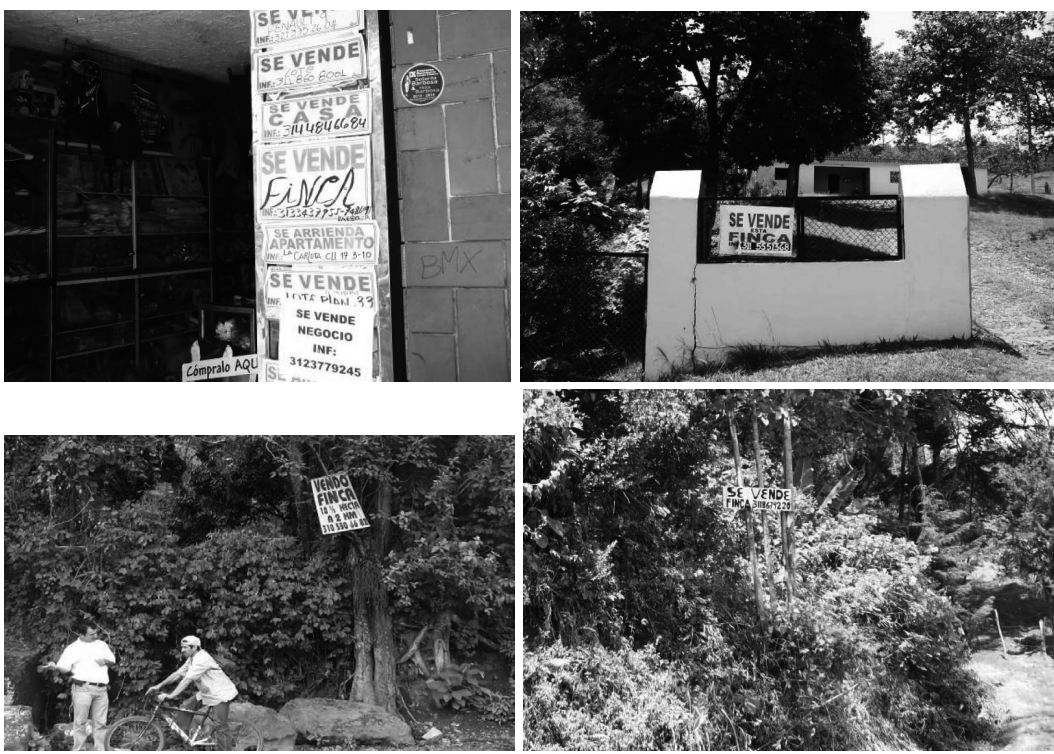

Fotografías: Ricardo Lozano-Botache 
La información tomada en campo es la misma que considera relevante la Norma técnica colombiana NTS I 02, expedida por el Instituto Colombiano de Normas Técnicas (Icontec) y el Registro Nacional de Avaladores (RNA) para avalúos rurales (Icontec-RNA, 2009), concurrente con los aspectos técnicos de la Resolución 620 de 2008 del Instituto Geográfico Agustín Codazzi, (IGAC, 2008) que básicamente incluye las siguientes variables: la clase agrológica, el tipo de uso agropecuario del suelo y la infraestructura productiva.

La información tomada en campo con los equipos Handheld mencionados fue descargada para geoproeso con el software ArcGis de la Universidad Santo Tomás. Con las herramientas de la aplicación mencionada se estructuraron bases de datos alfanuméricos y se relacionaron con bases de datos espaciales en formato vector y raster. Se logró entonces, con la opción de interpolación, la integración de los datos de encuesta, considerándolos ahora como un pixel o punto del mapa georreferenciado; el resultado fue el mapa de isoprecios o de tendencia del valor intrínseco de la tierra. Para la complementación del mapa en áreas no cubiertas por las encuestas se obtuvo el permiso de manejo de datos de la empresa Estudio T-Rural, agente del mercado inmobiliario que aportó vectores y puntos de precio que ha tomado durante el ejercicio de su objeto social valuatorio en el Departamento de Santander 2013. Estos datos también son manejados al amparo de las normas colombianas en cuanto a sus efectos legales.

\section{Resultados}

Durante la recolección de datos para esta investigación se confirmó que la disposición al cierre de transacciones de bienes inmuebles rurales de uso agropecuario, realmente se logra con contraofertas cercanas a $90 \%$ del valor de oferta o pedido, un valor más bajo no deja considerar una opción de venta dentro del mercado.

Se encontró que por la costumbre comercial en esta región de Colombia, Departamento de Santander, con 30,537 Km² y 2,030,775 habitantes, según el Departamento Nacional de Estadística DANE Colombia, se suele sobrevaluar la oferta inmueble rural y que las ofertas siempre llevan consigo el criterio de "negociables", sobre el entendido que hay una opción de rebaja en el precio de cierre o valor final de la transacción; al considerar este criterio se efectuaron las encuestas y fue posible indagar, por los componentes del precio de oferta, que al desagregarse, indicó el precio de la tierra por su valor intrínseco.

El concepto de valor intrínseco de la tierra no es desagregado en la valoración corriente de un predio durante una transacción, fue necesario 
explicarlo en todas las encuestas. El mercado de tierras no reconoce en la estimación de valor los tres componentes del precio de un bien inmueble de uso agropecuario: valor del suelo, valor de las coberturas del suelo o cultivos y valor de la infraestructura del predio.

En una misma zona rural, los derechos de propiedad formalmente conservados aseguran mejor precio en comparación con propiedades que no los poseen: la disminución del precio es de aproximadamente 50 por ciento.

El modelo de isoprecios que se generó sumando los datos y cartografía preliminar, entregada por la Universidad Santo Tomás (USTA) con las encuestas de campo, permite visualizar la tendencia del precio de la tierra de uso agrícola en el Departamento de Santander. A escala regional el precio alto es influido por los corredores viales troncales y transversales.

El mapa de isoprecios señala con mayor valor de las tierras de uso agrícola en el Departamento de Santander una zona en forma de corredor o franja a lo largo de la vía Bucaramanga-Bogotá, ésta es una vía troncal que comunica con la capital del país.

La zona de menor valor es la comprendida cerca a los corregimientos de Chingalé y Vijagual al extremo norte del departamento, esta zona esta desprovista de una red vial de primer orden y su comunicación es principalmente fluvial.

Al comparar los precios entre las zonas más y menos costosas, se evidencia que los suelos de importancia ambiental no reportan precios altos, en parte por las restricciones de uso del suelo.

Los datos permiten un modelo que puede ser permanentemente actualizado con información de valores reales de transacción. El modelo de manejo integrado de datos espaciales creado con la herramienta SIG es actualizable y dinámico, lo que permite efectuar análisis por periodos específicos y la elaboración de mapas de precios cuasihomogéneos o de isoprecios. Esto lo hace consolidable en el tiempo como un observatorio de la evolución del precio de la tierra.

Operar el modelo y mantenerlo con datos de transacciones reales permitirá hacer seguimiento y análisis de la variación regional del precio en relación con múltiples variables de observación que permitan aproximaciones a explicaciones desde la perspectiva social, económica y de modelos de ocupación del territorio. Desde esta perspectiva es posible coadyuvar con la transparencia de los mercados de tierras. 


\section{Gráfico 1}

\section{Mapa de los precios}

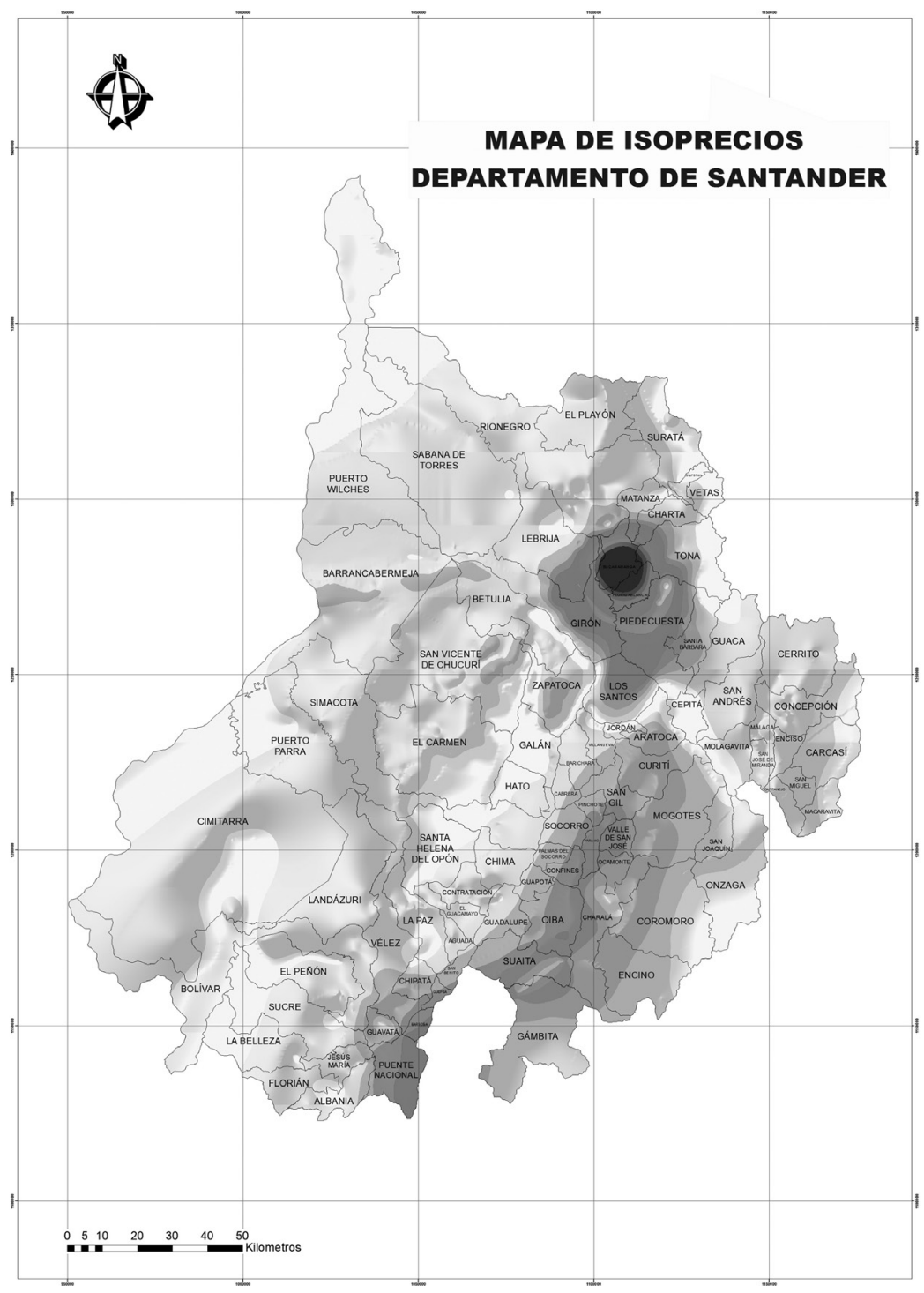

Fuente: elaboración propia con base en el manejo integrado de datos espaciales creado con la herramienta GIS. 


\section{Conclusiones}

El mapa de isoprecios creado y que se presenta a continuación como gráfico 1 puede ser operado en múltiples escalas y, opcionalmente complementado con otros documentos cartográficos para efectuar análisis más complejos de álgebra de mapas que son útiles en la planeación del uso del suelo y en el procesamiento de otros análisis geoespaciales multivariados.

Establecer convenios con entidades que operan precios reales como las lonjas de propiedad raíz, permitirá hacer cada vez más confiable el modelo hasta lograr que, por su consistencia, sea razonable dejarlo a la pública consulta en la web.

Este modelo no reemplaza la valuación normalizada de un avaluó comercial, pues desde la formulación del proyecto precisó que sólo intenta establecer tendencias del precio de la tierra por sus cualidades agrológicas, que son específicamente inherentes, aquí no se reconoce el valor de las coberturas o plantaciones ni de la infraestructura productiva y el nivel tecnológico de cada predio. Es posible desde este modelo iniciar otros de precios con usos diversos como el minero, las zonas de uso ambiental y los sumideros ambientales, entre otros.

Finalmente, un modelo es sólo una representación de la realidad explicada geométricamente y con sustento matemático, el cual puede resultar en términos económicos cierto dentro del marco céteris páribus, de forma que, como modelo predictivo, un sistema de información de precios de la tierra estará sujeto siempre a las consideraciones de valuación, esto es: un precio es válido sólo para un momento dado y en una circunstancia específica.

Los modelos de precios son explicativos y limitadamente predictivos. Al referirse a la conclusión estadística, Hawking y Mlodinow (2010) señalan que la utilización de términos probabilísticos para describir el resultado de los sucesos de la vida cotidiana no es un reflejo, pues, de la naturaleza intrínseca del proceso, sino tan sólo de nuestra ignorancia de algunos de sus aspectos; así, el modelo propuesto es sólo una aproximación al comportamiento del mercado como se entiende desde una toma de encuestas de ofertas de mercado y para condiciones sociales, económicas y políticas puntuales.

En 2014, el escaso y casi nulo número de investigaciones científicas, estudios de caso o documentos de política pública que se refieran al uso de la tecnología GIS, como herramienta para hacer transparentes los precios que operan en mercados de tierras de uso agropecuario y el subsecuente aseguramiento de los derechos de propiedad, señala que este campo es una posibilidad todavía inexplorada en el contexto latinoamericano, no obstante, el Plan Nacional de Desarrollo de Colombia 
2014-2018 "Todos por un nuevo país" presenta como una de las metas la implementación de un catastro multipropósito moderno, completo y permanentemente actualizado para garantizar la seguridad jurídica del derecho de propiedad de la tierra en Colombia.

Lo que se busca entonces, desde la iniciativa del gobierno colombiano, es tener un catastro a la medida de las necesidades del país, soportado en un GIS, que sea pieza fundamental del sistema de gestión de las tierras, principalmente para la legalización de la propiedad rural, la titulación de tierras baldías, la restitución de tierras despojadas, la adquisición directa de predios para ser repartidos y el otorgamiento del subsidio de reforma agraria, además de los reconocidos fines fiscales.

\section{Agradecimientos}

El autor reconoce el aporte ofrecido por Estudio T-Rural, empresa agente inmobiliaria dedicada a la valuación comercial de tierras, la cual prestó datos y apoyo logístico para la realización de este estudio. Los datos que Estudio T-Rural permitió usar, garantizaron la confidencialidad en el uso de información personal y del patrimonio que las leyes colombianas exigen.

\section{Fuentes consultadas}

Balcázar-Vanegas Álvaro, Nelson López, Martha Lucía Orozco y Margarita Vega (2001), Colombia: alcances y lecciones de su experiencia en reforma agraria, Cepal, Santiago de Chile.

Corte Constitucional de Colombia (2002), "Sentencia T-729. Habeas data y derecho a la información”, Corte Constitucional de Colombia, Bogotá, <http://www.corteconstitucional.gov.co/relatoria/2002/ t-729-02.htm>, 15 de agosto de 2013.

Diario Oficial (2011), Ley 1448, Artículo 72, “Acciones de restitución de los despojados", 48.096, Imprenta Nacional, <https://www.ictj. org/colombia-linea-tiempo/docs/Ley1448/ley1448.pdf>, 10 de julio de 2014.

Diario Oficial (1971), "Código de Comercio", emitido como Decreto 410 del 27 de marzo de 1971 y publicado en el Diario Oficial No. 33.339 del 16 de junio de 1971, <http://www.secretariasenado.gov.co/senado/basedoc/codigo_comercio.html>, $28 \mathrm{de}$ mayo de 2014. 
Deininger Klaus, Harris Selod y Tony Burns (2012), The land governance assessment framework. Identifying and monitoring good practice in the land sector, The World Bank, Washington.

DNP (Departamento Nacional de Planeación) (2011), "Plan Nacional de Desarrollo 2010-2014”, Departamento Nacional de Planeación de Colombia, Bogotá.

DNP (Departamento Nacional de Planeación) (2010), Documento Compes 3461, Política nacional para consolidar la interrelación del catastro y el registro, Consejo Nacional de Política Económica y Social, Bogotá.

FIG (International Federation of Surveyors) (2014), CADASTRE 2014 and Beyond, FIG Publication, Copenhagen.

Hawking, Stephen y Leonard Mlodinow (2010), The grand design, Editorial Paidós Mexicana, México.

Incoder (Instituto Colombiano de Desarrollo Rural) (1996), "Determinación de extensiones para las UAF's Resolución 41 asimilada del INCORA", <http://www.incoder.gov.co/documentos/Desarrollo_ Rural/Pedaf/Normatividad/RESOLUCI\%C3\%93N\%20 No\%20041\%20DE\%201996.pdf>, 12 de julio de 2013.

IGAC (Instituto Geográfico Agustín Codazzi) (2008), "Resolución 620 de 2008, por la cual se establecen los procedimientos para los avalúos ordenados dentro del marco de la Ley 388 de 1997", Bogotá, <http://www2.igac.gov.co/igac_web/normograma_files/ RESOLUCION\%20620+DE+2008.pdf>, 28 de mayo de 2013.

La República (2011), ¿Cuánto vale la Tierra?, Entrevista publicada en la versión digital el 31 de marzo de 2010, <http://www.larepublica.co/economia-cuanto-vale-la-tierra-_96792.php>, 2 de marzo de 2011.

Lawry Steven, Cyrus Samii, Ruth Hall, Aaron Leopold, Donna Hornby y Farai Mtero (2014), "The impact of land property rights interventions on investment and agricultural productivity in developing countries: a systematic review", Campbell Systematic Reviews, 1 (10), The Campbell Collaboration, pp. 1-104, doi: 10.4073/ csr.2014.1 
Ministerio de Minas y Energía de Colombia (2011), "Avance en el área minera contratada", <http://www.minminas.gov.co/minminas/ downloads/UserFiles/File/Minas_\%20Anllela/Estadisticas/ AREA_MINERA_CONTRATADA_dic_2010.pdf>, 10 de julio de 2013.

Ministerio del Interior y la Justicia (2010), “Decreto 4580. Por el cual se declara el estado de emergencia económica, social y ecológica por razón de grave calamidad pública", <http://wsp.presidencia.gov. co/Normativa/Decretos/2010/Paginas/Diciembre.aspx >, Ministerio del Interior y la Justicia, 12 de julio de 2014.

North, Douglas (1995), Instituciones, cambio institucional y desempeño económico, Fondo de Cultura Económica, México.

ORRDP (Observatorio de Restitución y Regulación de Derechos de Propiedad Agraria) (2014), "Tendencias en la restitución y redistribución de la tierra 2013”, ORRDP, Bogotá.

Pérez-Salazar Bernardo (2006), "Del 'cuerpo cierto' y otras ambigüedades...", Revista de Economía Institucional, 8 (14), Universidad Externado de Colombia, Bogotá, pp. 305-310.

Place, Frederick (1825), Cuerpo de leyes de la República de Colombia, GPD, $\mathrm{KHH} .40-1825$, V. 1, Imprenta Española de M.Calero-Goswel Road, Londres.

República de Colombia (2008), "Ley estatutaria 1266. Por la cual se dictan las disposiciones generales del habeas data y se regula el manejo de la información contenida en bases de datos personales, en especial la financiera, crediticia, comercial, de servicios y la proveniente de terceros países y se dictan otras disposiciones", Imprenta Nacional de Colombia, <http://www.imprenta.gov.co/ portal/page/portal/IMPRENTA/Productos/Diario_Oficial>, 3 de julio de 2014.

Rey, Dora Inés, Óscar Romero, Óscar Forero, Isabel Cristina Becerra (2014), "Unidad de Planificación Rural Agropecuaria", documento digital, UPRA, Bogotá.

Semana (2011), "Gobierno intervendrá la Superintendencia de Notariado y Registro”, Edición digital, publicada el 3 de marzo de 2011, 
Bogotá, <http://www.semana.com/nacion/articulo/gobiernointervendra-superintendencia-notariado-registro/236283-3>, 10 de julio de 2013.

Spichiger, Rachel, Rikke Brandt-Broegaard, Rasmus Hundsbæk-Pedersen y Helle Munk-Ravnborg (2013), "Land administration, gender equality and development cooperation. Lessons learned and challenges ahead", Danish Institute for International Studies, Copenhagen.

UN-Habitat (United Nations Human Settlements Programme-Habitat) (2008), Derechos seguros al suelo para todos, UN-Habitat, Nairobi.

Wallace, Judy (2009), "Making land markets work for all”, documento presentado en la sesión MKTl: Potential and Challenges for Land Markets at the FIG and World Bank Conference on Land Governance in Support of the MDGs. Responding to New Challenges, Washington DC, USA, 9-10 March 2009.

Recibido: 14 de octubre de 2014. Corregido: 11 de octubre de 2015. Aceptado: 12 de octubre de 2015.

Ricardo Lozano-Botache. Colombiano, magister en Desarrollo rural por la Universidad Javeriana de Colombia, magister en Administración de empresas por la Universidad Santo Tomás de Colombia y topógrafo por la Universidad del Tolima. Ha sido, desde 2001, profesor de la Facultad de Administración de Empresas Agropecuarias de la Universidad Santo Tomas de Colombia, tiene a su cargo las cátedras de Sociología Rural y Política Sectorial Agropecuaria, entre otras; algunas de sus publicaciones más recientes son: "Los derechos de propiedad sobre la tierra", Revista Lebret, vol. 1, Universidad Santo Tomas, Bucaramanga, pp. 1-93 (2009); "Los sistemas de administración de tierras como salvaguarda de los derechos de propiedad", Revista Lebret, vol. 1, Universidad Santo Tomas, Bucaramanga, pp. 191-215 (2010); "La topografía, perspectiva y formación de capacidades para el tercer milenio", Revista Anales de Ingeniería, 126 (928), Sociedad Colombiana de Ingenieros, Bogotá, pp. 60-65 (2013); en coautoría: Lineamientos y directrices de ordenamiento territorial para el Departamento de Santander, USTA, Bucaramanga (2014). 